\title{
Distributions of Aerosols in Sapporo in the Winter Season
}

\author{
By Tatsuo Endow and Choji Magono \\ Department of Geophysics, Hokkaido University, Sapporo \\ (Manuscript received 24 September 1970, in revised form 9 January 1971)
}

\begin{abstract}
Horizontal and vertical distributions of aerosols were measured with a condensation nucleus counter of Gardner type, in Sapporo in the winter season of 1970.

The concentration of aerosols in the city was in the order of $10^{4} \mathrm{~cm}^{-3}$ in the nighttime and $10^{5} \mathrm{~cm}^{-3}$ in the daytime, respectively. The concentration in the suburbs of the city was in the order of $10^{3} \mathrm{~cm}^{-3}$ both in the day and night time.

It was noted that the distributions were strongly influenced by meteorological conditions, that is, air with high concentration of aerosols was transported far to leeward by the surface wind. It was also noted that the concentration increased by photochemical reaction by about one order, while it decreased by snowfalls also by about one order.
\end{abstract}

\section{Introduction}

The air pollution in the city has become a serious problem. It is considered that the concentration of aerosols is a measure of the air pollution, because most of the impurities in the air form minute particles in their final states, however measurements of such distributions of aerosols have never been made in Japan.

When Dr. Schaefer visited Sapporo in the winter season in 1970 , he advised us to make measurements of aerosols, and made us a loan of a very convenient condensation nucleus counter of Gardner type which counts all kinds of condensation nuclei, e. g. aerosols. As a preliminary research of aerosols, the authors measured distributions of aerosols, utilizing the counter in Sapporo in February, March and April, 1970. This paper is a report of the results of the measurements.

\section{Method}

The condensation nucleus counter of Gardner type used, was of the expansion type whose maximum expansion ratio was 1.3 . This ratio corresponds to a saturation ratio of $600 \%$. In the actual measurements, a saturation ratio of $300 \%$ was used, because almost all kinds of condensation nuclei greater than $10^{-7} \mathrm{~cm}$ radius, e. g. Aitken nuclei, cloud nuclei and giant nuclei were counted within this saturation ratio. Accordingly particles counted in the present measurements showed a total concentration of such kinds of condensation nuclei, although most of them were occupied by the Aitken nuclei.

An observation car was used for the measurement of horizontal distribution of aerosols. An inlet was set at a corner of the roof of the car, and air was introduced into the counter by a tube. Individual measurements were made on a $2 \mathrm{~km}$ strip along the observation roads, stopping the engine of the car, and avoiding such times as when other cars were passing.

A ropeway was used for measuring the vertical distribution of concentrations of aerosols. The ropeway is located on the north-west slope of Mt. Moiwa to the south-east of Sapporo City and ranges from 50 to $450 \mathrm{~m}$ above the sea level.

\section{Results}

\subsection{Horizontal distributions}

Measurements of horizontal distribution of aerosol concentration were made in and outside of Sapporo, in order to have a rough image of aerosol distribution of the city, choosing days with a strong surface inversion. The measurements were made in the nighttime to avoid car congestions.

In Fig. 1, two solid lines show the observation roads in and outside of Sapporo. One road runs from a point indicated by $A$ at the left top corner to a point indicated by $B$ at the right bottom in the figure, and another road runs from point $B$ to a point $C$ at the right top corner. It took about two hours to make a series of measure- 


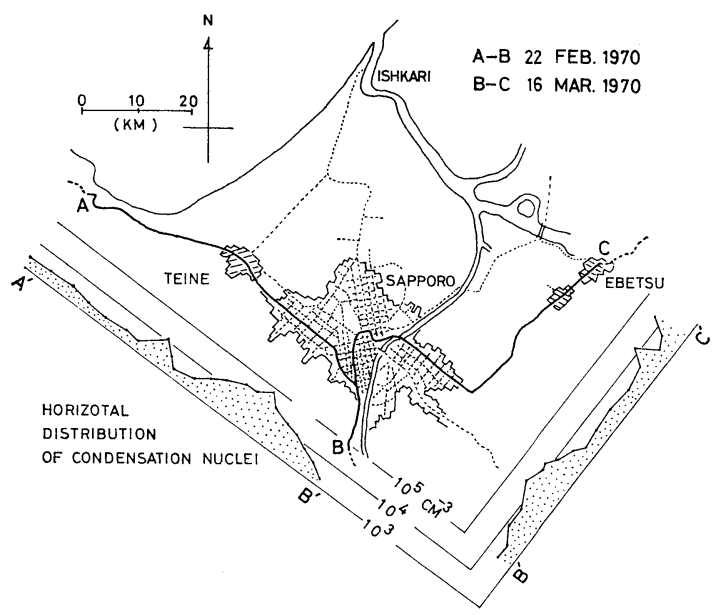

Fig. 1 Horizontal distributions of aerosols around Sapporo City.

ments for one run.

A horizontal distribution measured on Feb. 22 along the road $A B$ is projected on a line $A^{\prime} B^{\prime}$, as shown at the left bottom of the figure. It may be seen that the concentration of aerosols was steadily around $3 \times 10^{3} \mathrm{~cm}^{-3}$ in the suburbs of the city, while the concentration was increased to an order of $10^{4} \mathrm{~cm}^{-3}$ near the center of the city.

Another horizontal distribution on March 16 along the road $B C$ is shown on a line $B^{\prime} C^{\prime}$. It may be seen that the concentration was over $1 \times$ $10^{4} \mathrm{~cm}^{-3}$ in the cities of Sapporo and Ebetsu, while it was steadily about $3 \times 10^{3} \mathrm{~cm}^{-3}$ in the suburbs between the cities. Because the concentrations were in the order of $1 \times 10^{3} \mathrm{~cm}^{-3}$ in the suburbs where the air was not polluted directly by the human activity, the value of concentration of the order of $1 \times 10^{3} \mathrm{~cm}^{-3}$ was considered as a background for the air pollution in the city.

To measure the concentration within Sapporo City in detail, measurements were made on March 21 and April 13 along the observation roads, as indicated by crossed lines in Figs. 2 and 3. The observation road between points $E$ and $W$ in the figure runs from east to west, and the road between points $S$ and $N$ runs roughly from south to north through the city. The relation of the roads to the respective horizontal distribution is the same as in Fig. 1. White and black dots in Figs. 2 and 3 show the value of aerosol concentration in the daytime and nighttime respectively.

In the east and west distribution along the road

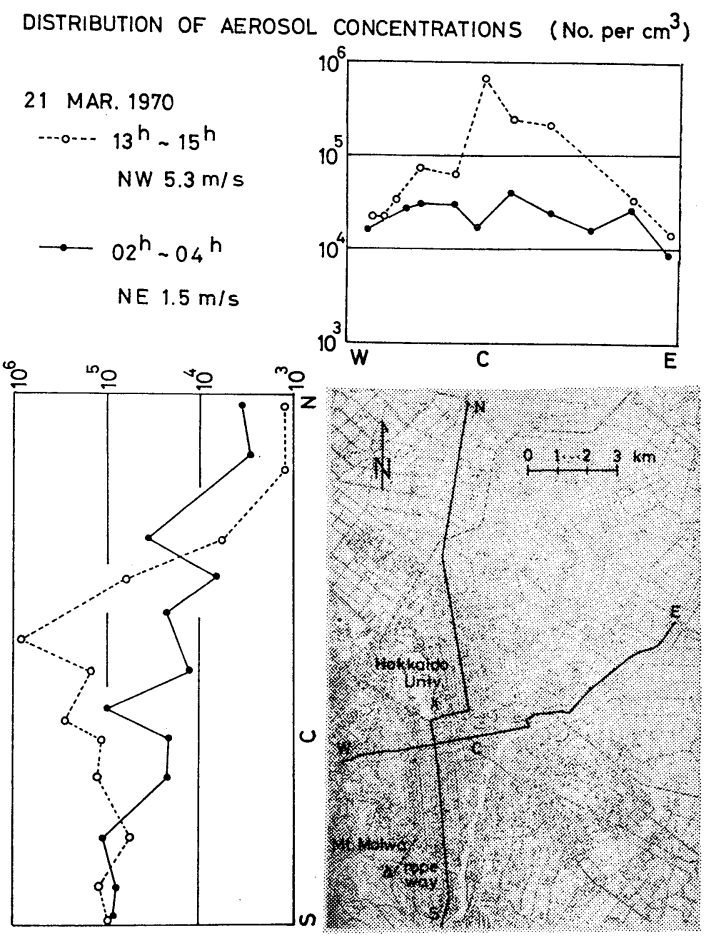

Fig. 2 Horizontal distributions of aerosols in Sapporo City under northerly wind.

DISTRIBUTION OF AEROSOL CONCENTRATIONS (No. per $\mathrm{cm}^{3}$ )

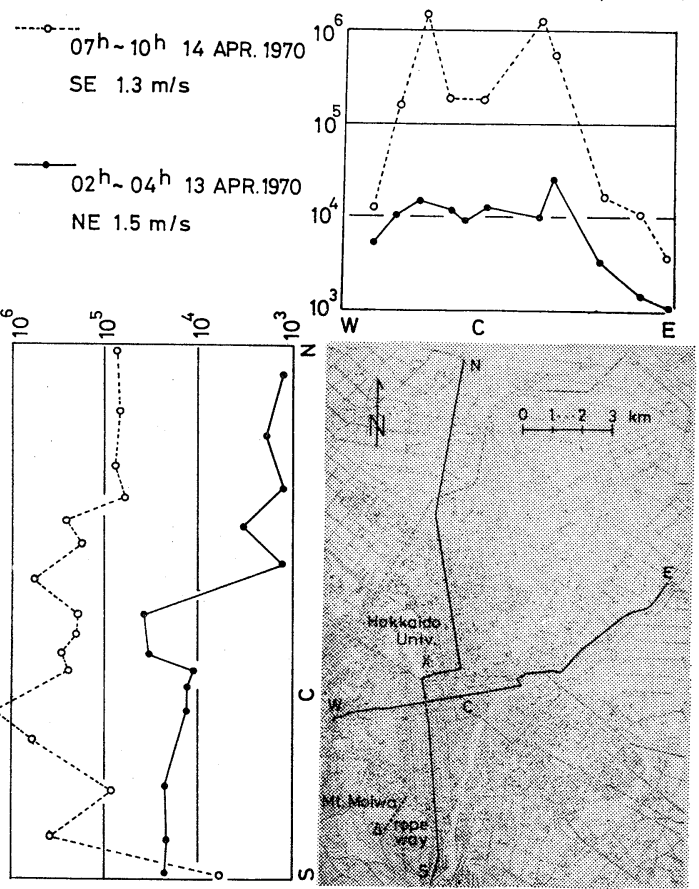

Fig. 3 Horizontal distribution of aerosols in Sapporo City under easterly wind. 
$E W$ shown at the top of Fig. 2, it may be seen that the nighttime concentration was in the order of $10^{4} \mathrm{~cm}^{-3}$, while the daytime concentration was markedly increased to the order of $10^{5} \mathrm{~cm}^{-3}$, reaching $8 \times 10^{5} \mathrm{~cm}^{-3}$ near down town Sapporo indicated by $C$. No remarkable change was observed in the concentration in the suburbs between the daytime and the nighttime.

A remarkable increase in the concentration near the down town area is also seen in the distribution of the south and north, as shown in the left hand of Fig. 2. However it was noted that concentrations in the northern portion is about two orders lower than in the southern portion. Particularly the concentration in the daytime near the north end was lower than in the nighttime and was as low as $1 \times 10^{3} \mathrm{~cm}^{-3}$. This low concentration in the northern portion may be explained by considering the topography around the city and the wind system at the observation time.

There are mountains of several hundred meter height to the south-west of the city, and the north-east side of the city opens onto a low flat plain. The Sea of Japan is located to the northwest of the mountains and the plain. It is considered that non-polluted air was transported from the sea by the prevailing north-westerly wind at a speed of $5.3 \mathrm{~m} \cdot \mathrm{sec}^{-1}$ in the daytime, then the concentration of aerosols decreased to a small value as low as $1 \times 10^{3} \mathrm{~cm}^{-3}$. Incidentally, the concentration in the sea breeze was in the order of $10^{2} \mathrm{~cm}^{-3}$.

In case of the measurements on April 13 and 14 , the concentration in the daytime was considerably higher than in the night time, nearly by two orders, as shown in Fig. 3. This difference $\mathrm{s}$ easily understood if we consider the prevailing wind during the days. It was fairly calm on both days. The wind speed ranged from 1.3 to $1.5 \mathrm{~m} \cdot \mathrm{sec}^{-1}$. At midnight of April 13, the concentration in the northern portion was as low as $2 \times$ $10^{3} \mathrm{~cm}^{-3}$, owing to the north-easterly wind. The next day, the wind direction changed to south-east.

As a result, air polluted by the city was blown to the foot of the mountain area where concentrations as high as $10^{5}$ to $10^{6} \mathrm{~cm}^{-3}$ were measured along the observation road $S N$. Then the highly polluted air was transported along the foot of the mountains far to the north-west. It was noted that the concentration was very low at the south end in the daytime. This suggests that the polluted air was produced in the city and was trans-

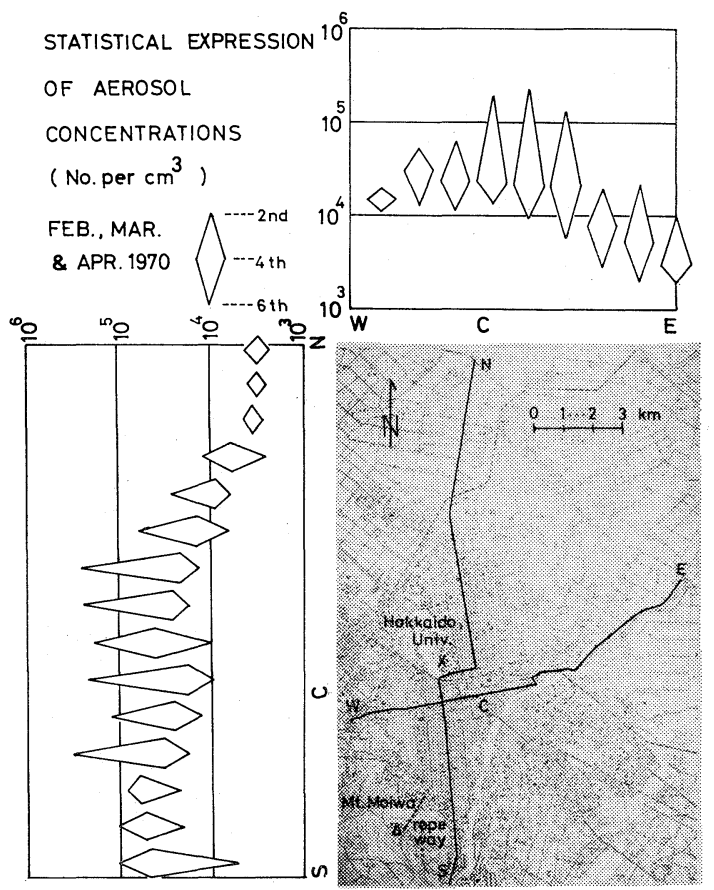

Fig. 4 Statistical expression of horizontal distribution of aerosols in Sapporo City in winter season.

ported to the north on the whole.

The results of seven measurements of horizontal aerosol distributions are shown by rhomb marks statistically in Fig. 4. In the rhomb marks the top and bottom of the rhombs show the second and sixth values in the seven values measured respectively, and the fourth value is shown by the height of the horizontal axis, eliminating the extreme values, e.g. the highest first and the lowest seventh values. It is seen in the figure that the concentration of aerosols was in the order of $10^{3} \mathrm{~cm}^{-3}$ in the suburbs of the city, while it increased to $10^{5}$ in the daytime and to $10^{4} \mathrm{~cm}^{-3}$ in the nighttime within the city.

\subsection{Diurnal changes}

Diurnal observations of aerosols were made in the campus of Hokkaido University which is located in the northern portion of the city.

Fig. 5 shows the results of measurements on April 25. Vertical and horizontal axes show concentrations per $\mathrm{cm}^{3}$ and time in hours respectively. Relating meteorological conditions are shown under the conditions. The concentration was in the order of $10^{4} \mathrm{~cm}^{-3}$ after the midnight of $24 \mathrm{th}$, then it gradually decreased. When the sun rose at 


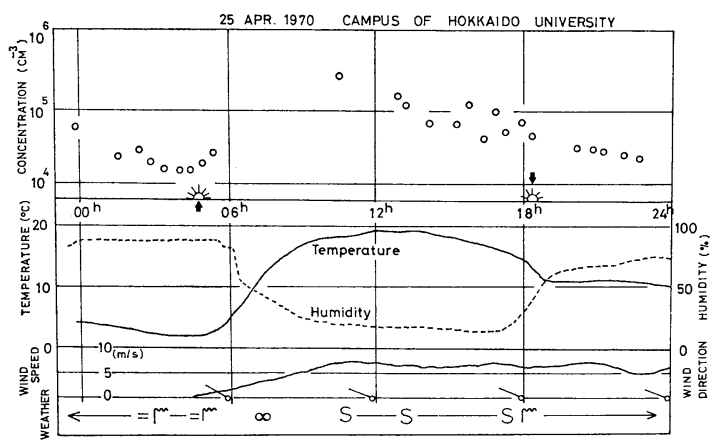

Fig. 5 A diurnal change in concentration of aerosols at the campus of Hokkaido University.

$05 \mathrm{~h} 10 \mathrm{~m}$ on 25 th concentration rapidly increased and it reached an order of $10^{5} \mathrm{~cm}^{-3}$ in the dayime, then it decreased gradually to an order of $10^{4} \mathrm{~cm}^{-3}$. After sunset at $18 \mathrm{~h} 10 \mathrm{~m}$, the values were steadily about $3 \times 10^{4} \mathrm{~cm}^{-3}$.

It may be seen in Fig. 5 that the concentration in the daytime was about one order higher than that in the nighttime, and the time change in the concentration was closely correlated to the sunrise and the sunset. It may also be seen that the pattern of the time change was exactly in parallel with that of the air temperature.

It was very calm before the sunrise, after which the wind speed increased gradually up to $7 \mathrm{~m}$. $\mathrm{ec}^{-1}$ and the speed remained nearly constant from sunset time through to midnight. The wind direction was steadily WNW throughout the day. It is therefore considered that the wind condition was not directly related the decrease in the concentration at sunset, although the time of the rapid increase in the morning coincided with the time of the sunrise.

It is a matter of course that the high concentration in the daytime was caused by human activity such as exhausted gases from car engines and smoke from chimneys of factories. However the beginning of the rapid increase in the aerosol concentration in the morning was about two hours earlier than that of the human activity. Accordingly it was considered that the rapid increase immediately after sunrise was caused by the effect of sunlight.

Fig. 6 shows another time change of aerosol concentration in the daytime on March 2. It was calm and cold in the forenoon, however in the afternoon the wind speed increased and changed ranging from 3 to $8 \mathrm{~m} \cdot \mathrm{sec}^{-1}$ and the air temper-

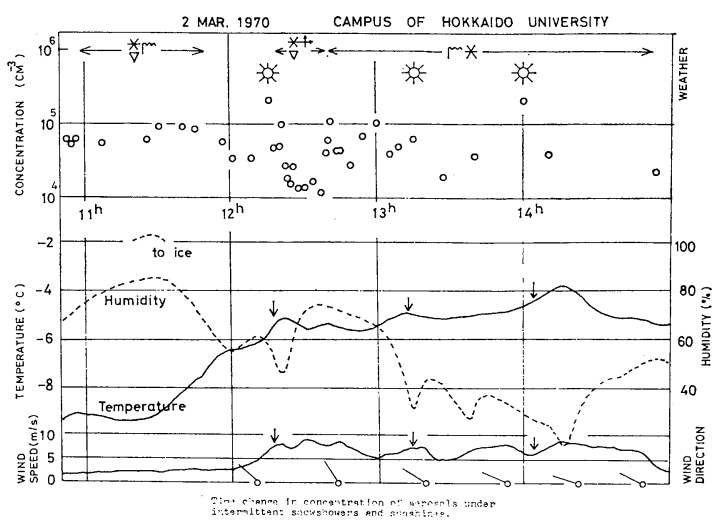

Fig. 6 Time change in concentration of aerosols under intermittent snowshowers and sunshines.

ature increased from -9 to $-5^{\circ} \mathrm{C}$. The relative humidity became low and was very changable according to the change in the temperature. That is to say, the weather was steady in the forenoon, then it became unsteady in the afternoon. Corresponding to the unsteady weather condition, the concentration of aerosols became changable in the afternoon.

It was generally cloudy in the afternoon, however the sun shone for several minutes at $12 \mathrm{~h} 15 \mathrm{~m}$, $13 \mathrm{~h} 15 \mathrm{~m}$ and $14 \mathrm{~h} 00 \mathrm{~m}$, as indicated at the top of Fig. 6. It may be noted that the short periods of sunshine coincided with the times of peaks of the concentration. It was also noted that the times of peaks roughly coincided with the times of increase in temperature and wind speed, as indicated by arrows. Considerations will be made later concerning those coincidences.

As seen at the top of Fig. 6, a violent snowshower occurred for about 30 minutes just after a period of sunshine at $12 \mathrm{~h} 15 \mathrm{~m}$. It was noted that the concentration was considerably lowered during the snowshower, that is to say it was about one order smaller than the neighbouring periods. This decrease in the concentration were considered to be caused by the effect of the snowfall.

\subsection{Vertical distributions}

Measurements of vertical distribution of aerosol concentration were made on a deep slope on the north-east side of Mt. Moiwa, utilizing the ropeway which has a $400 \mathrm{~m}$ altitude, as indicated at the bottom of Fig. 2. It was considered that the concentration there would be between the values of down town and the suburbs of the city, because 


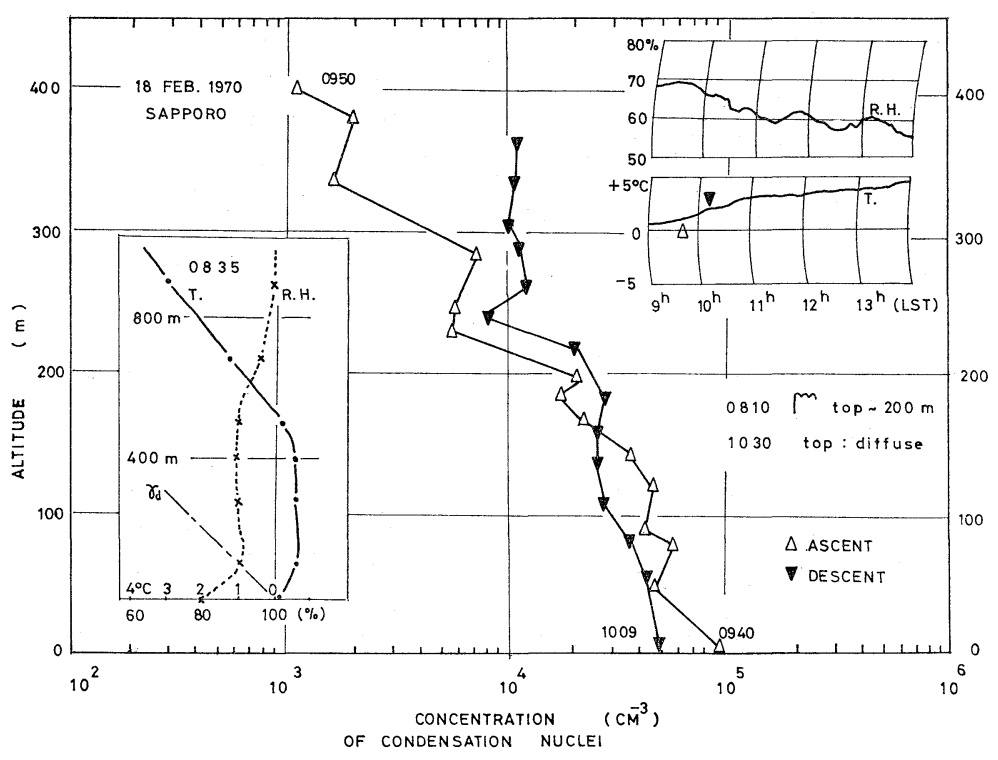

Fig. 7 Vertical distributions of aerosols in hazy weather.

the slope is located at the end of down town area.

Fig. 7 shows the results of measurements on Feb. 18. The weather was fine and a layer of haze was present. The measurements were made $\mathrm{i}^{\mathrm{n}}$ the morning when a surface inversion was still in existence, but on the other hand surface air temperature was rising. In the figure, vertical and horizontal axes show the altitudes above the base of the ropeway and the concentration at respective altitudes, respectively. The lines connecting the white triangles show the concentrations in the ascent, and the lines connecting the black triangles those in the descent, respectively. Radio sonde data obtained one hour before the measurement are shown in the lower left, and the surface air temperature and relative humidity are shown in the upper right portion of the figure.

When the measurement was started at $09 \mathrm{~h} 40 \mathrm{~m}$, the concentration at the base was as high as $1 \times$ $10^{5} \mathrm{~cm}^{-3}$, and the value gradually decreased as the ropeway gondola ascended. When the gondola passed $200 \mathrm{~m}$ altitude mark, the value rapidly decreased from $2 \times 10^{4}$ to $5 \times 10^{3} \mathrm{~cm}^{-3}$. The height of $200 \mathrm{~m}$ coincided with the top of the haze layer determined visually at $08 \mathrm{~h} 10 \mathrm{~m}$. Then it decreased again to a value as low as $1 \times 10^{3} \mathrm{~cm}^{-3}$ at the top of the ropeway. This value was the lowest in the present work.

Ten minutes were required to make a series of measurements of one ascent run. Ten minutes after the end of the ascent run, the concentration increased to a value of $1 \times 10^{4} \mathrm{~cm}^{-3}$ when the descent measurement was started. As the gondola descended, the concentration increased, particularly the rate of increase was extremely great at the $230 \mathrm{~m}$ altitude (a little higher than in the case of the ascent), then the concentration increased gradually and reached $5 \times 10^{4} \mathrm{~cm}^{-3}$ at the base.

These vertical distributions are, on the whole similar to the lower portion of the vertical distribution of Aitken nuclei measured by Wigand (1919) and Weickmann (1957).

During the measurement, the top of the haze layer gradually rose. It may be seen that the concentration of aerosols in the air layer lower than at the $230 \mathrm{~m}$ altitude was discontinuously higher than that in the upper layer. This altitude of $230 \mathrm{~m}$ was a little higher than the top of the haze layer determined at $08 \mathrm{~h} 10 \mathrm{~m}$. It may also be seen that the concentration in the descent increased in the layers above the haze layer, compared with that in the ascent run, while it decreased in the haze layer. This change in the vertical distribution between the ascent and the descent suggests that the grade of air pollution was made uniform and was diluted as far as the lower layer is concerned, owing to the gradual increase of the thickness of the mixing layer (haze layer).

Fig. 8 shows the result of the measurement which was made in the afternoon on March 21. There was no surface inversion and the lapse rate 
was considerably greater than that on Feb. 18, as seen in the left portion of Fig. 8. These conditions suggest that the lower air layer was not as steady as that on Feb. 18, in other words the vertical mixing became larger. It may be that according to the vertical mixing, the lapse rate in concentration as the ascent increased became very small, compared with that on Feb. 18.

When the ascent measurement was made, it was snowing, and when the descent measurement commenced, the snowfall had cleared up. Com- paring the distribution in the descent run with that in the ascent run, it was noted that the concentration decreased in the upper half on the whole, while it increased in the lower half. When the descent measurement was started at the top of the ropeway, the concentration was as low as in the fresh air in the suburbs of the city.

Considering the low concentration in the upper half in the descent run, it may be understood that the decrease was caused by an effect of the snowfall which was observed in the ascent run.

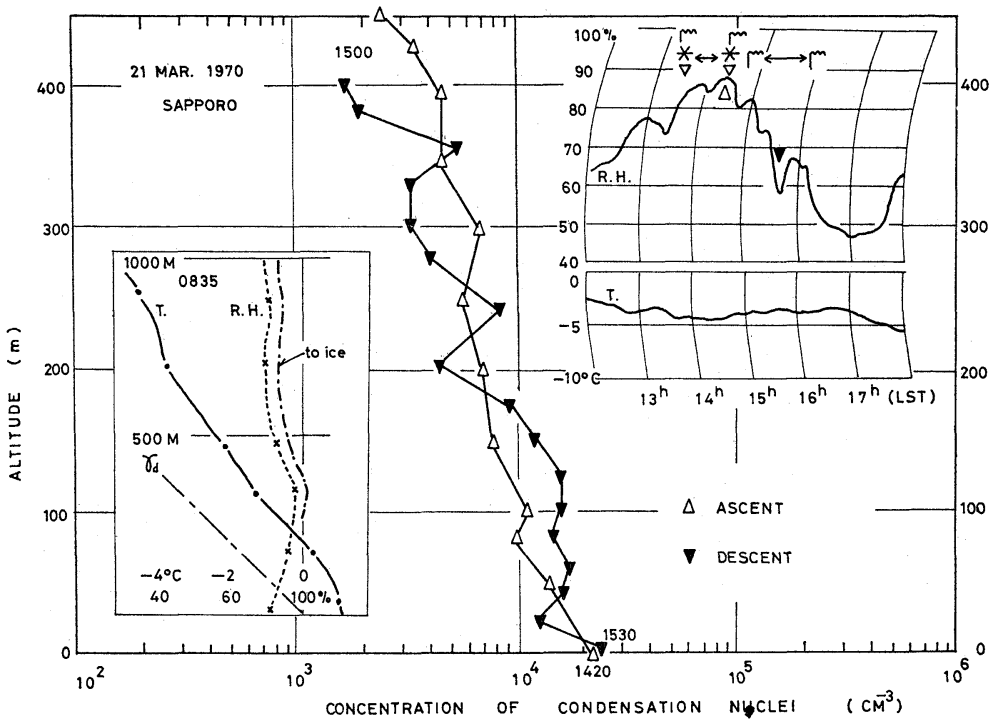

Fig. 8 Vertical distributions of aerosols in and after a snowshower.

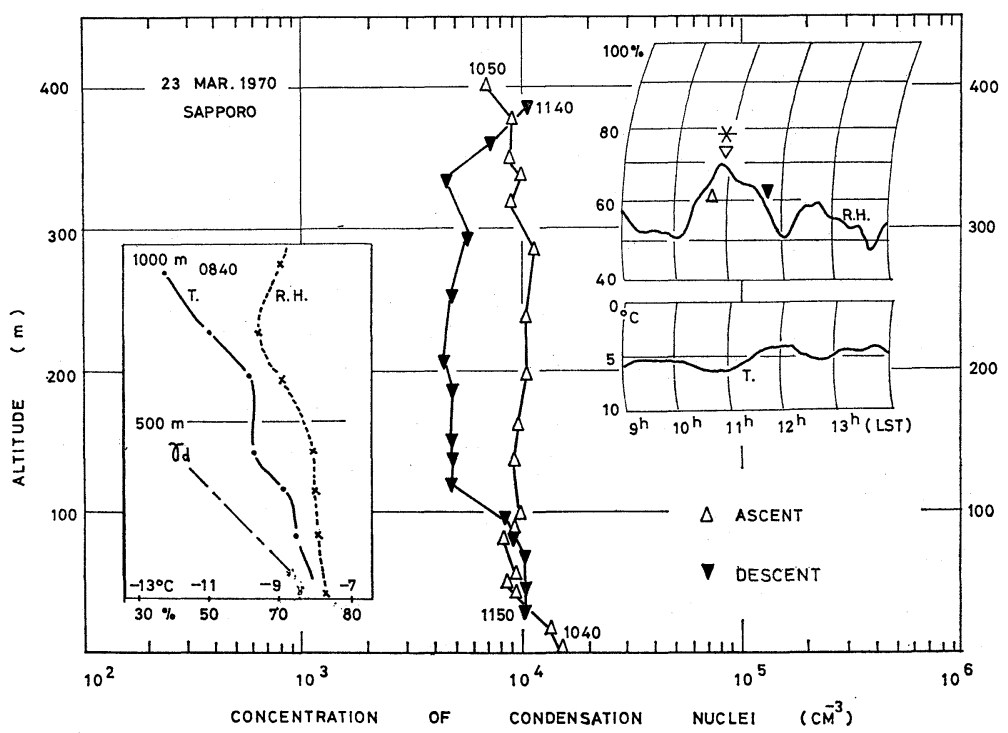

Fig. 9 Vertical distributions of aerosols in a snowshower. 
Although considerations concerning the effect of the snowfall will be made later, it may be noted that the humidity was fairly high during the measuring period, as shown in the right top of Fig. 8, particularly it was noted that the relative humidity with respect to the ice surface reached $100 \%$ or a little over ice saturation at the $400 \mathrm{~m}$ altitude, as seen in the vertical distribution of relative humidity in the left portion of the figure. In this case, the wash out by growing snow crystals were considered.

In case of the measurement in the morning on March 23, a snowshower occurred during the measurement, and the concentration was fairly low on the whole, as seen in Fig. 9. In the figure, it is noted that the concentration in the descent was considerably lower than that in the ascent, except for the layer lower than $100 \mathrm{~m}$ altitude. This remarkable decrease in the layer above the $100 \mathrm{~m}$ altitude was clearly affected by the snowfall. In this case, the relative humidity was not so high as to reach ice saturation.

\section{Considerations}

The result of measurements in the present work may be summarized as follows.

1. The concentration of aerosols was in the order of $10^{3} \mathrm{~cm}^{-3}$ in the suburbs of Sapporo, and was of $10^{4}$ in the nighttime; and it was $10^{5}$ in the daytime respectively within the city. The high concentration air mass in the city shifted far to the leeward by the surface wind.

2. In addition to the effect of human activity, a photochemical effect by sunlight was observed in the time change in the aerosols concentration.

3. On calm days, the concentration of aerosols was very high in the exchange layer which height was lower than that in the stable layer. As the thickness of the exchange layer increased, the concentration was diluted. This is a well known phenomenon.

4. By the effect of snowfalls, the concentration in the lower layer decreased, while an increase was seen in the layer immediately above the ground surface.

The concentrations of aerosols in the suburbs and within the city were nearly the same as the old data in 'country inland' and in 'city' obtained by Landsberg (See Mason, 1957). And the vertical distribution of aerosols was just similar to the lower portion of average vertical distribution of Aitken nuclei which were measured by Wigand

\section{(1919) and Weickmann (1957).}

Because the aerosols originate from the ground surface and human activity, it is a matter of course that the result of the present work was nearly the same as the old data, however it should be noted that the present measurements were generally made when the surface was covered by fallen snow. If the surface was exposed to wind, the concentration would be much higher.

The concentration within Sapporo City was also nearly the same as those in cities in the State of New York which were recently measured with a counter of the same type as the present counter by Hogan (1970). And the increase with amount of one order in the daytime was also common to the results obtained by him in winter season.

Concerning the rapid increase in aerosol concentration in the sunshine on March 2, considerations were made as follows. The air temperature and wind speed were also increased at the times. It is considered that the air became less stable owing to heating of the ground surface by the sunlight. Therefore two possible explanations are considered for the rapid increase in aerosols in the sunshine. One is the photochemical effect on the aerosols. If hygroscopic acid particles such as $\mathrm{H}_{2} \mathrm{SO}_{4}$ particles are formed by the photochemical reaction, concentrations of aerosols (condensation nuclei) will increase rapidly in the sunshine.

Another is the effect of the turbulence. When the air becomes less stable, air turbulence will occur. If the concentration of aerosols in an air layer a little higher than the ground surface, the concentration at the ground surface will increase by the vertical mixing of the turbulence. However taking into account the fact that the rapid increase coincided with the sunshine in time and that the amount of the increase was about one order, the authors consider the rapid increase in aerosol concentration was mainly caused by the effect of some photochemical reaction, although the mechanism is not yet clarified. Bricard et al (1968) and Kojima et al (1970) also found a considerable increase in aerosol concentration in their laboratory experiments.

As seen in Fig. 6, during a snowshower the concentration was rapidly decreased by about one order, and as seen in Figs. 8 and 9, the concentration in lower layers except for that near the ground surface was considerably lowered after a snowfall. It was clear that the decrease in the 
concentration was caused by some effect of the snowfall. Concerning this effect the following three explanations are considered.

It may be considered that aerosols are transported toward growing snow crystals by the Stefan flow (vapor flux). However, because the air was not always saturated with respect to the ice surface and snow crystals usually do not grow in lower layers such as $200-400 \mathrm{~m}$ altitude, it is difficult to consider that the Stefan flow was the main mechanism for the washing out by the snow crystals.

It is generally known that air becomes very clear after a rain or snowfall. In this case, it is considered that aerosols in the air were merely swept out by the falling raindrops or snow crystals, although concerning the collection efficiency no detailed informations are given.

The third explanation is the replacement of air by down draft accompanied by a rainfall or snowfall. It is believed that a showery snowfall accompanies appreciable amount of down draft. If the amount of the down draft reaches a certain value, considerable fresh air will be brought down to the lower air layer from above and will replace the polluted air. This explanation is supported by the observational fact that the concentration of aerosols in fresh air accompanied by the snowfall was in the same order as that of non-polluted air in the suburbs of the city.

\section{Conclusional remarks}

The concentration of aerosols in Sapporo in the winter season showed reasonable distributions, and its values were in same order as those in great cities in the State of New York.

Rapid increases due to the photochemical effect were observed in concentration of aerosols.

The clearing phenomena by snowfalls were considered, and it was concluded that the sweeping out by falling snow crystals and the replacement of air due to falling snow crystals were the main mechanisms for the clearing phenomena of aerosols.

\section{Acknowledgements}

The authors thank Dr. Schaefer of the Atmospheric Sciences Research Center, the State University of New York at Albany who advised us to make the measurement and kindly loaned us a convenient condensation nucleus counter. Without the counter, such a measurement was impossible in present day in Japan.

\section{References}

Bricard J., F. Billard and G. Madelaine, 1968: Formation and evolution of nuclei of condensation that appear in air initially free of aerosols. $J$. Geophys. Res. 73, 4487-4496.

Hogan, A. W., 1970: After private information.

Kojima, H., T. Sekikawa, F. Tanaka and T. Yoshioka, 1970: On the aerosols produced by chemical reaction. Third Meeting of the Atmospheric Research Group of Japan in Kyoto.

Mason, B. J., 1957: The Physics of Clouds, Oxford Press, P. 41.

Weickmann, H., 1957: Recent measurements of the vertical distribution of Aitken nuclei. Artificial Stimulation of Rain, Pergamon Press, London, 8188.

Wigand, A., 1919: Die vertikale Verteilung des Kondensationskerne in der Freien Atmosphäre. Ann. Phys., Lpz., 59, 689-742.

\title{
冬の札幌におけるエアロソルの分布
}

\author{
遠藤辰雄 - 孫野長治 \\ 北海道大学理学部地球物理学教室
}

1970年の冬，札幌市内外でガードナー型の凝結核装置によってェアロゾルの水平ならびに垂直分布の測定を拈こな った．測定結果によれば，札幌市内のェアロゾルの濃度は夜間は $10^{4} / \mathrm{cm}^{3}$ ，日中は $10^{5} / \mathrm{cm}^{3}$ の桁であり，郊外では昼 夜とも $10^{3} / \mathrm{cm}^{3}$ の桁であった.

市内のエアロゾルの濃度分布は気象条件によって強く支配され，高濃度の大気は地上風によって遠く風下に運ばれ る。また日射によって濃度が 1 桁も増大し，降雪によって一桁も減少することもわかった。 